\title{
Premise Acceptability, Deontology, Internalism, Justification
}

\section{James B. Freeman Hunter College, CUNY}

Key words: warrant, presumption, acceptability, justification, internalism, externalism.

Abstract: Acceptability is a thoroughly normative epistemic notion. If a statement is acceptable, i.e. it is proper to take it as a premise, then one is justified in accepting it. We also hold that a statement is acceptable just in case there is a presumption of warrant in its favor. We thus see acceptability connected to epistemic normativity on the one hand and to warrant on the other. But there is a distinct tension in this dual connection. The dominant tradition in modem epistemology sees epistemic justification as an internalist notion. We are justified in holding a belief just in case certain conditions are fulfilled of which we have privileged access. Warrant is an externalist notion. We have no privileged access to the conditions of warrant. Is our understanding of acceptability as both normative and definable in terms of presumption of warrant philosophically coherent? We shall argue that it is a philosophically coherent notion. Presumption of warrant, unlike warrant, is an internalist notion. Our position can be characterized as an externalist internalism. It avoids the charge brought against extemalism of allowing one to be justified in accepting some claim even if one has no evidence for it. We meet the classical internalist challenge that acceptance is normatively proper only if one has done one's epistemic duty and thus one is aware of the normative propriety of the acceptance by providing a non-deontological definition of epistemic justification, and arguing that this is still a sufficiently normative notion for acceptability.

To say that a statement or claim (on our belief) is acceptable for a given person is to say that it is proper, correct for that person to accept it, i.e. take it as a premise for further deliberation or action. ${ }^{1}$ Acceptability then is a thoroughly normative notion. Being acceptable amounts to being epistemically justified. We need to make this plain since "acceptable" has another distinct sense, that of "being marketable." In this sense, a claim is acceptable if some audience would accept it, regardless of whether audience members had any epistemic justification for doing so. This would indicate the claim's persuasive force with the audience, but not its acceptability. We are not concerned with such a rhetorical sense of acceptability. We are concerned here with analyzing a thoroughly normative concept. In previous papers we have argued that acceptability amounts to presumption, more specifically challenger presumption. ${ }^{2}$ In a dialectical exchange, a challenger plays the role of asking for justification of claims which a proponent makes, including justification in the light of objections the challenger may raise. There is a presumption in favor of a claim from the challenger's point of view just in case the challenger is obliged to concede the claim. Her objections have been answered and asking for further evidence would be otiose. We have argued in another previous paper ${ }^{3}$ that presumption amounts to presumption of warrant. Following Alvin Plantinga, we see four factors determining whether a belief has warrant: the mechanisms producing the belief must be functioning properly; they must be operating in a cognitive environment for which they are suited; they must be operating according to a design plan or aspects of a design plan aimed at 
arriving at the truth, and the objective probability must be high that operating in this manner will reach the truth. A statement is acceptable for a challenger then just in case there is a presumption from the challenger's point of view that these four conditions are satisfied. Repeating our arguments for these claims is beyond the scope of this paper. We thus see acceptability connected to epistemic normativity on the one hand and to warrant on the other.

But there is a distinct tension in this dual connection. The dominant tradition in modern epistemology, from Descartes and Locke through contemporary analytic philosophy, sees epistemic justification as an internalist notion. We are justified in holding a belief just in case certain conditions are fulfilled of which we are directly aware, to which we have some sort of privileged access. Warrant is an externalist notion. We have no privileged access to the conditions of warrant the way we have privileged access to our own internal states, nor are these conditions of warrant, when they hold, self-evident to us in any other way. Is our understanding of acceptability as both normative and definable in terms of presumption of warrant philosophically coherent?

This paper aims to show that this understanding of acceptability is philosophically coherent. We must begin by observing that warrant and presumption of warrant are two different things. There may very well be a presumption of warrant for a belief and yet the belief itself not be warranted. We may see this readily by looking at one of the famous Gettier counterexamples to the claim that knowledge is justified true belief: Smith and Jones have applied for a certain job. The president of the company has told Smith that Jones will get the job. Also, Smith has counted the number of coins in Jones' pocket and found that there are ten. Smith then has strong evidence, surely evidence sufficient to justify belief, that

(d) Jones is the man who will get the job, and Jones has ten coins in his pocket. ${ }^{4}$

But, by the substitutivity of identity, (d) entails

(e) The man who will get the job has ten coins in his pocket.

Gettier continues,

Let us suppose that Smith sees the entailment from (d) to (e), and accepts (e) on the grounds of (d), for which he has strong evidence. In this case, Smith is clearly justified in believing that (e) is true. But imagine, further, that unknown to Smith, he himself, not Jones, will get the job. And also, unknown to Smith, he himself has ten coins in his pocket. Proposition (e) is then true, though proposition (d), from which Smith inferred (e), is false. ${ }^{5}$

So here Smith has a justified true belief which is not knowledge.

Is Smith's belief warranted? It is not, for it fails the second and fourth conditions for warrant. The mechanism generating Smith's belief that Jones will get the job involves taking testimony from the company president. That the president's testimony was false constitutes a defect in the cognitive environment. Given this defect, the objective probability of coming to a true conclusion from this false premise is not high-certainly it is not high enough for warrant. As 
Plantinga analyses the situation, taking testimony as a belief generating mechanism

is designed to operate in the presence of a certain condition: that of our fellows knowing the truth and being both willing and able to communicate it. In the absence of that condition, if it produces a true belief, it is just by accident, by virtue of a piece of epistemic good luck: in which case the belief in question has little or nothing by way of warrant. ${ }^{6}$

But is there a presumption of warrant for (e) from Smith's point of view? It would certainly seem that in most cases there would be. For given that Smith has been appeared to in this auditory manner,' why should he need any argument to convince him that his hearing and language understanding capacities are functioning properly, that the company president was speaking clearly through a non-distorting medium, that he had no extra-cognitive interest in this matter, and that the testimony of the company president speaking about company business is reliable? Smith would need arguments for any of these points only if he had objections to bring against them. But why should we suppose that he had? So while Smith's belief that (d) Jones will get the job is not warranted, nor is his belief that (e) the man who will get the job has ten coins in his pocket, we may take it that there is a presumption of warrant for (e) from Smith's point of view. Warrant and presumption of warrant then do not amount to the same thing.

Since warrant and presumption of warrant are distinct, we can ask whether presumption of warrant is an externalist notion, as is warrant. We can readily show that presumption of warrant is an internalist rather than externalist notion. Presumption of warrant is a matter of direct awareness. It is something of which we may become directly aware. Let us review the four conditions of presumption of warrant, considering a concrete case. Suppose I have the perceptual belief that there is a tree in front of me outside my office window and there is a presumption of warrant for that belief. It follows that I am appeared to treely and that I am aware of no objection to the claim that my perceptual faculties are functioning properly or of any reason to question or demand evidence for their proper function. Even if the object of our consciousness, what it intends, is the tree as opposed to our being appeared to treely, we are conscious that we are appeared to treely and can turn our attention to being thus appeared to. ${ }^{8}$ Likewise, it is a matter of my consciousness, of what I am aware of, that I lack awareness of factors calling the proper function of my perceptual mechanism into account and I can turn my awareness to such lack of awareness. So awareness of proper function is a matter of my consciousness. I have direct access to the factors determining this presumption. By properly turning my attention, I may become explicitly aware of them. Awareness of cognitive malfunction would be a matter of direct awareness and $\mathrm{I}$ have direct access to the lack of such awareness.

Likewise, given that I have a presumption of warrant for my belief, I am aware of no reason to think that the environment is distorting or misleading. Lack of such awareness is part of my consciousness, and it is something to which I have direct access. Again, although I might be quite surprised to find the tree 
outside my office window gone and indeed sorry that it was gone, I am conscious of no reason to think that its loss would cause my psychic fragmentation. But this betokens the fact that $I$ am conscious of no reason to think that in forming the belief that there is a tree in front of me, my belief-generating mechanisms are operating according to specifications in my design plan aimed other than at the truth. Again, although this lack of awareness may not be the intensional object of my consciousness, as part of my consciousness, it is something to which I have direct access. Finally, my visual perception has been basically trustworthy in the past. I am conscious of no reason to think that my design plan when aiming at the truth through visual perception is unreliable. This again, as an aspect of my consciousness, is something to which I have direct access.

So for all four conditions of presumption of warrant, I may have direct access to whether those conditions hold from my point of view. Presumption of warrant, then, as opposed to warrant is an internalist notion. Although there may be a presumption of warrant for a belief from my perspective without my being explicitly aware of that presumption, without my state of belief or consciousness intending that presumption, the factors determining it are nonetheless open to my direct awareness. By defining acceptability in terms of presumption and showing that presumption for a belief amounts to presumption of warrant for that belief, we have set forth an internalist account of acceptability. A belief is acceptable, from my point of view as challenger, just in case I am not aware of factors which would indicate that the belief is not warranted. Since warrant is an externalist notion while lack of consciousness of the factors spelling failure of warrant is a matter of internal, direct access, we may say that we are here presenting an externalist internalism. ${ }^{*}$

Our view thus avoids the rather obvious charge brought against externalism of allowing one to be justified in accepting some claim even if one has no evidence for it. Although some externalists may have a more sophisticated view, on a basic externalist account of justification, a belief is justified if it is produced by a reliable mechanism, if a person's holding that belief is a sufficient condition for the belief to be true. Notice one need have no knowledge of this connection for one's belief to be justified. Indeed one's belief will be justified even if one is aware of no reasons for the belief. As long as there is a lawlike relation making one's believing that $p$ a sufficient condition that $p$ be true, even if this relation is completely external to awareness, one is justified in believing that $p$. But why should this be so? It seems quite unintuitive. Why should one's belief be justified if one has nothing resembling evidence or reasons for it; if, from one's perspective, "it is an accident that the belief is true?"10

That our notion of presumption of warrant avoids this objection altogether is obvious from our argument that presumption of warrant is an internalist notion. The believer has access to all four conditions for the presumption of warrant, and if these are all satisfied, surely the belief is not seriously unreasonable or unwarranted from his or her point of view. Intuitively, there being a presumption of warrant would seem to make accepting a statement eminently reasonable or 
justified. But can our position provide a satisfactory account of acceptability? Showing that it is satisfactory involves showing that our view is defensible against other charges which can be brought against it on internalist lines. To see how a problem arises, let us consider how we might further characterize a normative notion of acceptability.

To say that a claim is acceptable from a challenger's point of view, that the challenger ought to concede the statement, could be said to indicate that the challenger is within his or her epistemic or doxastic rights in accepting that statement; one violates no epistemic or doxastic duty in accepting that statement. One is justified in accepting it. In this explication of normativity, we make contact with other normative notions_-epistemic rights and duties, being epistemically justified. What we must now ask is whether having a presumption of warrant for a claim is sufficient for one to be within one's rights in accepting that claim, for this acceptance to be epistemically justified. What is the nature and ground of epistemic rights or of epistemic justification? Now rights and duties concern what is obligatory. That makes these notions deontological from the Greek déon for that which is obligatory. "What then have philosophers said about doxastic or epistemic obligation?

We must first note a feature of obligation simpliciter. We may distinguish subjective and objective obligation. We have a subjective duty to perform some action when we believe that we have a duty to perform that action and we have arrived at that belief in a conscientious manner. Our judgment is an expression of a properly informed conscience. We would hold a person blameworthy for going against his or her properly informed conscience. But we might also hold that the person's "real" duty lies elsewhere, that the person's judgment, though sincere, is mistaken. He or she has not correctly apprehended what objective duty requires. Some other action would be the person's subjective duty if we could convince that person of it.

As Plantinga points out, for both Descartes and Locke, objective epistemic duty and subjective epistemic duty coincide for a significant number of cases, those where we can just see where our objective epistemic duty lies (provided we are functioning properly). For Descartes, for example, it is our objective duty to accept nothing but what can be seen with sufficient clarity and distinctness. But if someone does transgress this objective duty, we would hold him blameworthy. Hence accepting only what can be seen with sufficient clarity and distinctness is also one's subjective duty.

This coincidence of subjective and objective duty leads to internalism. These cases where we can just see that accepting certain beliefs is objectively permissible epistemically are cases where we have internal access to the conditions of objective epistemic permissibility. A proposition's being certain, being sufficiently clear and distinct, is what makes accepting it objectively right or permissible. But certainty or self-evidence is something to which we have internal access. It is because of this internal access that subjective epistemic duty and objective epistemic duty coincide on these cases. I want to call attention to 
one feature in particular of classical internalism: It involves what we might call a meta-awareness. I am not only internally aware of certain evidence, which would justify certain of my beliefs, I am aware that it justifies those beliefs. For Descartes, this would mean being aware that being clear and distinct or based on ideas which are clear and distinct makes a judgment acceptable, and being aware not only of clear and distinct ideas but that they are clear and distinct. If we are within our epistemic rights, we are aware that we are within our epistemic rights.

It is precisely here that our view comes into conflict with classical internalism. If there is a presumption for a belief for a particular person qua challenger, need the challenger be aware of that presumption? In other words, is there a presumption for the challenger's belief from her perspective only if she has determined that there is such a presumption by determining or recognizing that a suitably favorable indicator is present in these circumstances and no already-justified counterindicators are likewise present? If a belief is presumptively justified for a challenger, must she recognize that the belief is presumptively justified? Is this a necessary condition for its being presumptively justified for the challenger? The claim that it does clashes with what we apparently recognize concerning our accepting or assenting to many presumptively acceptable beliefs. Coming to believe and further accept a presumptively acceptable statement is frequently something immediate. Should I see a 10 ton tractor trailer hurtling down the highway towards me on a collision course and take evasive action, my believing that this object was coming at me and my accepting that belief by using it as a premise for action are immediate. I accept that premise without any thought or conscious recognition of whether there is a presumption in its favor. I am appeared to in a certain way; I have no evidence of perceptual malfunction, or that my environment fosters illusory appearances, or that I have a psychic need to see 10 ton tractor trailers hurtling towards me, or that my visual perceptual mechanism in general has been unreliable. There is a presumption from my point of view for the claim that there is a 10 ton tractor trailer coming at me, although I have not accepted the claim in the light of such a presumption. It is a basic belief and I have accepted it immediately. Hence we distinguish between there being a presumption for a statement for the challenger at a particular point and recognizing, determining, or establishing that there is such a presumption.

But what then of the challenger who accepts immediately a basic belief she has formed for which there is a presumption from her point of view. She has given no thought to the issue of presumption. The internalist meta-awareness condition is not satisfied. Does that mean that the challenger has been derelict in her duty in accepting this statement? If so, does that mean that her acceptance was not normatively proper or acceptable, and that any theory which says it was is deficient as a normative theory of acceptability? This is the challenge that classical internalism poses for our view and I want to meet it head on. Surely, if there is any sense in which we can do our epistemic duty with respect to our beliefs or be epistemically responsible in the beliefs we hold, those beliefs will be 
based on adequate evidence. Surely also we would not be doing our epistemic duty if despite having adequate evidence, we also had sufficient evidence to the contrary and yet accepted our belief. Let us say that a belief is epistemically justified if it is based on adequate evidence in the absence of sufficient overriding reasons to the contrary. This is virtually the definition William Alston gives of epistemic justification, in contrast to deontological justification, in his paper "Concepts of Epistemic Justification."

$\mathrm{S}$ is epistemically justified in believing that $p$ iff S's belief that $p$ was based on adequate grounds and $S$ lacked sufficient overriding reasons to the contrary. ${ }^{12}$

Now surely it would seem that if I am appeared to in the manner of a 10 ton trailer rushing at me and I have no evidence of perceptual malfunction of any sort compromising a presumption of warrant, then I have adequate evidence for my belief. In the sense of epistemic justification that we have just defined, we want to say that the belief is justified. But notice that our belief may be epistemically justified without our being aware that it is epistemically justified. We can have adequate grounds for our belief without being aware of their adequacy. Requiring awareness of their adequacy is part of internalism. We can then see deontology as having two distinct implications - justification and internalism. Since deontology leads to internalism and internalism is in conflict with our position, the question arises: Is epistemic justification adequate for a normative account of acceptability? Is internalism with its meta-awareness requirement needed in addition for a proper account of normativity? I shall argue that it is not.

Notice that there are areas of human activity where an action may be normatively acceptable, right, and yet speaking of it as a duty or as being in accord with duty would strain our notion of fulfilling one's duty. At least one such area is that of using language correctly according to the grammar and syntax of some language. One who has mastered a natural language, gained some degree of fluency in it will speak and write according to grammatical and syntactical rules without consciously appealing to those rules while using language. The resulting discourse will conform to grammatical rules, the language use will be normatively correct and acceptable - at least grammatically and syntactically - but would it be right to say that the person was doing his linguistic duty in performing those actions which constitute his discourse? Does the question of duty even arise here? Can we say the speaker is within his linguistic rights in using the linguistic constructions he did? Although rules of grammar and syntax may be formulated for a language, we follow them not by conscious intention but by unreflective habit.

To speak of accomplishing one's duty, do we not have to consciously apply some rule in an action? Is this not a necessary condition for subjective duty? Ideally, should not the aim be, as Gilbert Meilaender phrases it, that "each moral agent should act self-consciously, aware of the grounds upon which he acts and prepared to defend those grounds"13? This clearly contrasts markedly with correctly speaking a language, at least in most cases. Unreflective usages of language, matters of skill, acquired habit, will be nonetheless normatively correct 
and acceptable. But surely when we say that someone's speech is grammatically correct or we say that someone is grammatical, i.e. his speech is standardly grammatically correct, we are making a normative judgment, indeed a normative judgment about a type of behavior or activity. So normativity in general does not presuppose deontology.

I claim that normativity does not presuppose deontology in the sphere of accepting claims or beliefs either. I see accepting claims or beliefs as a practice, analogous to the practices of speaking a language or swimming. A full argument for this would involve looking at the mechanisms which generate beliefs and showing in each case how accepting such beliefs is a practice. That is clearly beyond the scope of this paper. But we point out here that like the practices of language use and swimming which we perform voluntarily but immediately, without conscious reference to rules governing those practices, so we accept beliefs immediately, without explicit reference to the conditions which justify that acceptance. Yet as uses of language or moves in swimming are proper if done according to the rules, so acts of acceptance are proper, acceptable, if done in the light of or in response to certain conditions. Those conditions are precisely that there be a presumption of warrant for the belief or claim from the point of view of the person doing the accepting as challenger. In this way we meet the challenge of internalism, providing a normative account of acceptability which is nonetheless not deontological and so does not entail internalism.

What we have shown or at least indicated in this paper is that we can give a normative account of acceptability in terms of presumption of warrant according to which someone's accepting a claim or belief will be acceptable even if that person cannot show that it is acceptable. A belief's being acceptable for a challenger does not presuppose her recognizing that the belief is acceptable or having reasons to show it acceptable. Thus acceptance can be immediate and yet acceptable, if there is a presumption of warrant for the claim. I think this is crucial, since much of our acceptance is immediate. Any adequate account of premise acceptability that hopes to be applicable in the evaluation of real world arguments needs to develop an account of acceptability which allows certain cases of immediate acceptance to be acceptable and yet is normative. I hope I have at least indicated how that challenge can be met in this paper.

${ }^{1}$ In characterizing acceptance in this way, we are following L.J. Cohen's distinction of belief from acceptance in An Essay on Belief and Acceptance (Oxford: Clarendon Press, 1992), see especially $\mathrm{Ch} . \mathrm{l}$.

"See in particular "A Dialectical Approach to Statement Acceptability," Proceedings of the Second International Conference on Argumentation, ed. Frans H. van Eemeren, Rob Grootendorst, J. Anthony Blair, and Charles A. Willard (Amsterdam: Sic Sat, 1991), pp. 338347.

3 "Consider the Source: One Step in Assessing Premise Acceptability" Analysis and Evaluation (Proceedings of the Third International Conference on Argumentation, vol. 2), ed. 
Frans H. van Eemeren, Rob Grootendorst, J. Anthony Blair, and Charles A. Willard (Amsterdam: Sic Sat, 1995), pp. 203-09.

4 The lettering of this and Gettier's other example statements is taken from his paper, "Is Justified True Belief Knowledge?" Analysis 23 (1963), pp. 121-23.

${ }^{5}$ Gettier, p. 122.

${ }^{6}$ Alvin Plantinga, Warrant and Proper Function (New York: Oxford University Press), pp. 3435.

7Some may find our use of "to appear" in the passive voice unconventional and thus perhaps disconcerting. But there is philosophical precedent for this usage, certainly in Plantinga's work on warrant, and a distinct philosophical rationale. To say that someone was appeared to in a certain way describes a putative fact of sensation, or more generally experience, without making any commitment as to what appears. Indeed, the phrase does not even tempt us to make such commitments. Thus to say that Jones was appeared to "green treely" describes Jones' sensory experience, but it does not make any commitment as to whether a green tree, an object in the external world, appeared to Jones or whether certain sense data appeared to him. The phrase suggests no reification of appearances. The passive voice together with adverbial modification lets us avoid getting needlessly embroiled in these issues of the philosophy of perception.

${ }^{8}$ This is what Thomas Reid calls reflection. See Essays on the Intellectual Powers of Man (Indianapolis: Hackett Publishing Company, Inc.), p. 153.

9 To play, obviously, on the title of William Alston's paper, "An Internalist Externalism," Synthese 74 (1988), 265-83.

${ }^{10}$ Laurence BonJour, The Structure of Empirical Knowledge (Cambridge: Harvard University Press), p. 43, italics in original.

"See Alvin Plantinga, Warrant: The Current Debate (New York: Oxford University Press), p. 12 , footnote 27.

${ }^{12}$ William Alston, "Concepts of Epistemic Justification." Monist 68 (1985), p. 77.

${ }^{13}$ Gilbert C. Meilaender, Faith and Faithfulness: Basic Themes in Christian Ethics (Notre Dame and London: University of Notre Dame Press), p. 5.

JAMES B. FREEMAN DEPARTMENT OF PHILOSOPHY HUNTER COLLEGE, CUNY 695 PARK AVENUE NEW YORK, NY I002I 